\title{
Puff-by-puff Mainstream Smoke Analysis by Multiplex Gas Chromatography-Mass Spectrometry*
}

\author{
by
}

Charles E. Thomas, Kent B. Koller

Philip Morris USA, P. O. Box 26583, Richmond VA 23261

\section{SUMMARY}

A puff-by-puff mainstream smoke procedure has been developed that provides the sensitivity and selectivity of a gas chromatography-mass spectrometry (GC-MS) system. The smoke analysis is based on automated sample collection and injection into the GC system. This development builds on, and complements, prior puff-by-puff procedures developed by Philip Morris USA, that utilized infrared (IR) analysis of gas-phase mainstream smoke. IR analysis of the gas-phase smoke for individual smoke constituents relies on the unique spectroscopic absorption patterns of each analyte. The new multiplex procedure relies on both chromatographic separation as well as spectroscopic separation. A significant feature of this method is that multiple injections are made prior to the complete elution of the first injected sample. The benefits of this methodology are that both sensitivity and the number of detected compounds are enhanced. While the multiplex method increases the complexity of the chromatographic data, the mass spectral analysis provides a means for data reduction to meaningful results. Many smoke constituents that are at concentrations below the Fourier transform infrared (FTIR) detection limit are observable with the multiplex analysis while maintaining the feature of puff-by-puff characterization of fresh smoke. The gas-phase mainstream smoke filtration performance of standard adsorption materials are discussed as a demonstration of the versatility and information content of this analytical procedure. [Beitr. Tabakforsch. Int. 19 (2001) 345-51]

\section{ZUSAMMENFASSUNG}

Es wurde ein Verfahren zur zugweisen Analyse des Hauptstromrauchs von Cigaretten entwickelt, dessen Untersuchungsgenauigkeit und Selektivität der Gaschromatographie-Massenspektrometrie (GC-MS) entspricht. Die Rauchanalyse basiert auf einer automatisierten Probensammlung und Einspritzung in das GC System. Diese Methode ist eine Weiterentwicklung und Ergänzung früherer Verfahren, die zur zugweisen Untersuchung der Gasphase des Hauptstromrauchs mittels Infrarotanalyse (IR) von Philip Morris USA entwickelt wurden. Die IR-Analyse der Gasphase zur Bestimmung einzelner Rauchbestandteile beruht auf den spezifischen Absorptionsspektren jeder einzelnen Substanz. Das neue multiplexe Verfahren beruht sowohl auf der chromatographischen als auch auf der spektroskopischen Trennung. Ein besonderes Kennzeichen dieser Methode ist es, dass mehrere Einspritzungen vor der vollständigen Elution der zuerst eingespritzten Probe erfolgen. Der Vorteil dieser Methode besteht darin, dass sie nicht nur genauer ist, sondern auch mehr Substanzen bestimmt werden. Während die multiplexe Methode die Fülle an chromatographischen Daten erhöht, bietet die massenspektroskopische Analyse ein Instrument zur Datenreduzierung und somit zur Ermittlung brauchbarer Ergebnisse. Viele Rauchinhaltsstoffe, die in Konzentrationen unterhalb der Bestimmungsgrenze der Fourierspektroskopie (FTIR) liegen, sind bei der zugweisen Analyse frischen Rauches mit der multiplexen Analyse 
erkennbar. Die Fähigkeit von Standard-Adsorptionsmaterialien, die Gasphase des Hauptstromrauchs zu filtern, wird unter dem Gesichtspunkt diskutiert, die Vielseitigkeit und Aussagefähigkeit dieses analytischen Verfahrens aufzuzeigen. [Beitr. Tabakforsch. Int. 19 (2001) 345-51]

\section{RESUME}

Une méthode d'analyse bouffée par bouffée de la fumée du courant principal, qui offre la précision et la sélectivité d'un système chromatographie en phase gazeuse spectrométrie de masse (GC-MS), a été mise au point. L'analyse de la fumée est basée sur le prélèvement automatisé de l'échantillon et son injection dans le système GC. Ce développement poursuit et complète les méthodes d'analyse bouffée par bouffée mises au point par Philip Morris USA antérieurement, et qui étaient basées sur l'analyse infra-rouge de la phase gazeuse du courant principal. L'analyse infra-rouge de la phase gazeuse des composants individuels de la fumée est basée sur les spectres d'absorption spectroscopiques spécifiques de chaque composant. La nouvelle procédure multiplex tient à la fois de la séparation chromatographique et spectroscopique. Une caractéristique importante de cette méthode est la réalisation d'injections multiples effectuées avant l'élution complète de la première injection. Les avantages de cette méthode sont une précision accrue et une augmentation du nombre des composés détectés. Tandis que la méthode multiplex accroît la complexité des données chromatographiques, l'analyse par spectrométrie de masse offre un moyen de réduire les données pour aboutir à des résultats compréhensibles. De nombreux constituants présents dans la fumée, en concentrations inférieures à la limite de détection par spectrométrie infra-rouge à transformée de Fourier (FTIR), sont détectables au moyen de l'analyse multiplex, tout en examinant la fumée native bouffée par bouffée. La capacité de filtration de la phase gazeuse du courant principal par les divers matériaux d'absorption est discutée, pour démontrer la précision et la performance de cette procédure analytique. [Beitr. Tabakforsch. Int. 19 (2001) 345-51]

\section{INTRODUCTION}

Several research efforts at Philip Morris USA are focused on cigarette design and filtration materials that may effect changes in smoke chemistry. A key evaluation parameter of cigarette prototypes is the analytical analysis of the composition of the mainstream smoke. A single general screening procedure is useful for rapid evaluation of multiple samples and provides guidance towards further investigation of promising cigarette prototypes. The use of gas chromatography with a mass spectrometer (GC-MS) provides analytical benefits of sensitivity and selectivity and has been a research tool at Philip Morris USA since 1956 for evaluation of smoke samples collected from cigarettes (1). Typically, data are collected from a single sample per chromatographic evaluation. The use of Fourier transform infrared (FTIR) spectroscopy combined with a single puff collection and analysis system (2) provides puff-by-puff data on multiple gases in fresh smoke. The sensitivity of FTIR spectroscopy does not match the capabilities of the GC-MS systems. The FTIR smoke constituent data from the individual puffs of a single cigarette provides insight on the effects of cigarette design on smoke chemistry but is limited to a 12 to 15 gas-phase compounds, a few of which are carbon dioxide, carbon monoxide, acetaldehyde, hydrogen cyanide and nitric oxide.

A novel GC-MS method has been developed for the puffby-puff analysis of individual gas-phase components of cigarette smoke that combines the benefits of the puffby-puff analysis capabilities of the FTIR system with the sensitivity of the GC-MS system. The method was specifically developed to measure the selective filtration of tobacco smoke. It is able to measure the relative concentrations of 25 different gas-phase compounds in each and every puff of a single cigarette. The collection and analysis of the smoke is automated and begins less than $5 \mathrm{sec}$ after each puff has been taken. The compounds measured represent a broad spectrum of the classes of compounds found in smoke. They include aliphatic hydrocarbons such as ethane, propene, butadiene and isoprene; aromatic hydrocarbons such as benzene and toluene; and aldehydes including formaldehyde, acetaldehyde and acrolein. The method also measures selected nitriles, ketones, furans, sulfides, mercaptans and pyrroles in the gas phase.

\section{EXPERIMENTAL AND PROCEDURES}

\section{Instrumentation}

The GC-MS instrumentation consisted of a HP 5971 mass selective detector connected to a HP 5890 GC with electronic pressure control from Agilent Technologies Inc., Palo Alto, California, USA. The smoking machine used was a KC Automation programmable, single-port, syringe smoking machine from KC Automation, Richmond, Virginia, USA. Sample introduction was via an automated injection system (see text).

\section{Chromatographic conditions}

The chromatographic column used was a J\&W DB- $5 \mathrm{~ms}$ that was $60-\mathrm{m}$ long, had a $0.25-\mathrm{mm}$ i.d., and a $1.0-\mu \mathrm{m}$ film thickness (pt no. 122-5563, J\&W Scientific, Inc., California, USA). The initial GC instrumental conditions used in the method set the split/splitless injector temperature at $150^{\circ} \mathrm{C}$, the column oven at $30^{\circ} \mathrm{C}$, the column flow at $1.0 \mathrm{~mL} / \mathrm{min}$, and the MS detector transfer line at $180^{\circ} \mathrm{C}$. 


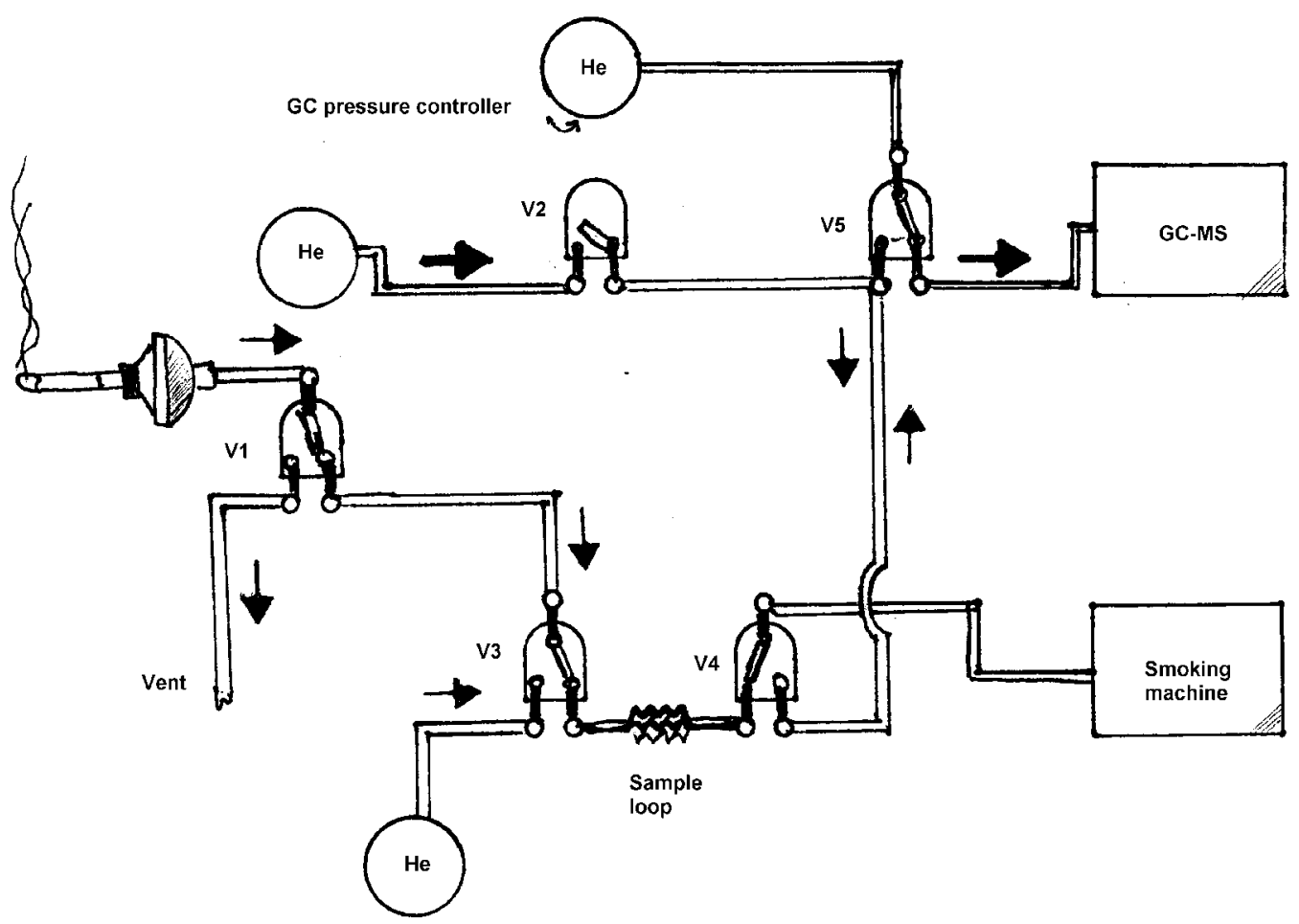

Figure 1.

Schematic of the automated smoke injection system

The injector split ratio was 60:1. These column conditions result in an initial inlet pressure of 15.3 psi. For the chromatographic analysis, the column oven is programmed to remain at $30^{\circ} \mathrm{C}$ for $17 \mathrm{~min}$, then ramped to $125^{\circ} \mathrm{C}$ at $5^{\circ} \mathrm{C} / \mathrm{min}$. At $125^{\circ} \mathrm{C}$, the ramp rate is changed to $25^{\circ} \mathrm{C} / \mathrm{min}$ with a final oven temperature of $250^{\circ} \mathrm{C}$. This temperature is maintained for $10 \mathrm{~min}$. The total run time is $51 \mathrm{~min}$ (data collection started at $t=3.0 \mathrm{~min}$ as 0 $\mathrm{min})$. The MS settings consist of a source vacuum of approximately $4.0 \times 10^{-5}$ and a transfer line temperature of $180^{\circ} \mathrm{C}$. Ion count data were collected for scan masses of 20 to $120 \mathrm{amu}$ for $t=0.0$ to $23 \mathrm{~min}$ and for scan masses of 30 to $180 \mathrm{amu}$ for $t=23$ to $48 \mathrm{~min}$.

\section{Materials and samples}

All reference and test cigarettes in this study were either standard Kentucky reference $1 \mathrm{R} 4 \mathrm{~F}$ cigarettes or fabricated using $1 \mathrm{R} 4 \mathrm{~F}$ rods. All materials added to filters were inserted into the filter in a plug/space/plug configuration. The space was a fully filled cavity 2.5 to $5 \mathrm{~mm}$ long, ending $5 \mathrm{~mm}$ from the butt end. Dilution was prior to the space and unchanged from the $1 \mathrm{R} 4 \mathrm{~F}$ control. The carbon used was Pica part no. G55C-8, $14 \times 40$ mesh (Pica USA, Inc., Columbus, Ohio, USA). All cigarettes were lit using the Borgwaldt electric lighter and smoke was sampled using a standard Cambridge filter pad.

\section{Automated smoking system}

The automated injection system is a series of solenoids that operate in a specific sequence to collect and inject an aliquot of helium pressurized gas-phase smoke into the injector of the GC-MS instrument. A schematic of this system is shown in Figure 1. The injection system is interfaced to the $\mathrm{KC}$ automation smoking machine via four auxiliary relays whose timings are integrated into the smoking machine programming. The system can be programmed for up to 15 puffs per cigarette, but is usually set for the first eight puffs to keep data analysis manageable.

After a smoking run has been initiated, the following sequence of events takes place for each puff. A 2-sec puff of $35-\mathrm{mL}$ volume is drawn through the automated system into a sampling loop. Three seconds later, V1, V3, and V4 are actuated. This isolates the smoke in the sample loop and pressurizes it with helium that is equalized to the GC injector inlet pressure. At $5 \mathrm{sec}$ after the puff, V5 is actuated for $2 \mathrm{sec}$. When this valve is actuated, the helium pressurized smoke replaces the feed helium to the GC injector and a portion of the gas-phase sample is swept onto the column. After V5 is deactivated, V2 is activated and $\mathbf{V} \mathbf{3}$ is deactivated. This purges the residual smoke from the system. At $55 \mathrm{sec}$ after the puff, all of the valves are deactivated and the system is ready for the next puff.

\section{Compounds measured by the method}

Twenty-five gas-phase and semi-volatile compounds were selected from a list of over a hundred different compounds that had been identified in prior studies of gasphase smoke under similar conditions as having sufficient concentration and sample resolution. These $25 \mathrm{com}-$ 
Table 1.

Quantitation ions and individual puff retention times for compounds measured in the method

\begin{tabular}{|c|c|c|c|c|c|c|c|c|c|}
\hline \multirow{2}{*}{$\begin{array}{l}\text { Compounds measured in } \\
\text { gas phase smoke }\end{array}$} & \multirow{2}{*}{$\begin{array}{l}\text { Quantitation } \\
\text { ion }\end{array}$} & \multicolumn{8}{|c|}{ Retention times for each puff (min -3.0$)$} \\
\hline & & Puff 1 & Puff 2 & Puff 3 & Puff 4 & Puff 5 & Puff 6 & Puff 7 & Puff 8 \\
\hline Argon & 40 & 2.30 & 3.30 & 4.30 & 5.29 & 6.29 & 7.29 & 8.28 & 9.28 \\
\hline Carbon dioxide & 45 & 2.37 & 3.36 & 4.36 & 5.36 & 6.36 & 7.35 & 8.35 & 9.34 \\
\hline Propene & 42 & 2.76 & 3.77 & 4.76 & 5.76 & 6.75 & 7.75 & 8.75 & 9.74 \\
\hline Hydrogen cyanide & 27 & 3.03 & 4.03 & 5.03 & 6.02 & 7.02 & 8.01 & 9.01 & 10.00 \\
\hline Ethane & 30 & 2.44 & 3.44 & 4.44 & 5.43 & 6.43 & 7.43 & 8.42 & 9.42 \\
\hline Propadiene & 40 & 3.04 & 4.04 & 5.02 & 6.03 & 7.02 & 8.01 & 9.02 & 10.01 \\
\hline 1,3-Butadiene & 54 & 3.85 & 4.85 & 5.85 & 6.84 & 7.84 & 8.83 & 9.83 & 10.83 \\
\hline Isoprene & 67 & 7.31 & 8.30 & 9.30 & 10.27 & 11.27 & 12.27 & 13.08 & 13.90 \\
\hline Cyclopentadiene & 66 & 9.21 & 10.22 & 11.22 & 12.14 & 13.00 & 13.80 & 14.55 & 15.26 \\
\hline 1,3-Cyclohexadiene & 79 & 17.39 & 17.83 & 18.25 & 18.66 & 19.05 & 19.43 & 19.81 & 20.17 \\
\hline Methyl cyclopentadiene & 79 & 17.72 & 18.14 & 18.54 & 18.96 & 19.31 & 19.68 & 20.03 & 20.39 \\
\hline Formaldehyde & 30 & 2.68 & 3.64 & 4.68 & 5.67 & 6.66 & 7.66 & 8.64 & 9.65 \\
\hline Acetaldehyde & 43 & 3.59 & 4.59 & 5.58 & 6.58 & 7.58 & 8.57 & 9.57 & 10.56 \\
\hline Acrolein & 56 & 6.16 & 7.15 & 8.15 & 9.14 & 10.13 & 11.13 & 12.09 & 12.98 \\
\hline Acetone & 58 & 6.40 & 7.39 & 8.39 & 9.38 & 10.37 & 11.37 & 12.30 & 13.18 \\
\hline Diacetyl & 86 & 13.04 & 13.78 & 14.46 & 15.10 & 15.70 & 16.28 & 16.83 & 17.35 \\
\hline Methyl ethyl ketone & 72 & 13.68 & 14.37 & 15.01 & 15.61 & 16.18 & 16.73 & 17.25 & 17.76 \\
\hline Cyclopentanone & 55 & 26.54 & 26.64 & 26.74 & 26.84 & 26.94 & 27.06 & 27.16 & 27.27 \\
\hline Benzene & 78 & 18.93 & 19.26 & 19.64 & 19.99 & 20.32 & 20.64 & 20.96 & 21.27 \\
\hline Toluene & 91 & 25.48 & 25.61 & 25.74 & 25.87 & 26.00 & 26.13 & 26.26 & 26.28 \\
\hline Acrylonitrile & 52 & 8.08 & 9.07 & 10.07 & 11.06 & 12.02 & 13.07 & 13.70 & 14.46 \\
\hline Methyl furan & 82 & 14.44 & 15.06 & 15.65 & 16.22 & 16.75 & 17.27 & 17.76 & 18.24 \\
\hline 2,5-Dimethyl furan & 96 & 21.86 & 22.09 & 22.31 & 22.53 & 22.74 & 22.95 & 23.16 & 23.36 \\
\hline Hydrogen sulfide & 34 & 2.61 & 3.61 & 4.60 & 5.59 & 6.59 & 7.59 & 8.59 & 9.58 \\
\hline Carbonyl sulfide & 60 & 2.80 & 3.81 & 4.80 & 5.80 & 6.79 & 7.80 & 8.79 & 9.78 \\
\hline Methyl mercaptan & 47 & 4.31 & 5.30 & 6.30 & 7.29 & 8.29 & 9.29 & 10.26 & 11.26 \\
\hline Methyl pyrrole & 81 & 23.88 & 24.05 & 24.22 & 24.38 & 24.54 & 24.70 & 24.86 & 25.01 \\
\hline
\end{tabular}

pounds are listed in Table 1. Each compound was positively identified by mass spectral comparison of reference compounds and/or library reference spectra. A suitable ion for measurement, and the retention times, for each compound were determined for each puff and are listed in Table 1.

\section{Measurement procedures}

Compound concentrations can be reported as percent $v s$ control for each puff or as a percent $v s$ control for total delivery. There are no calibration chemical standards employed in this method. Instead, the 1R4F reference cigarette serves as the control standard. The concentrations of the individual compounds are reported as relative percentages compared to the gas-phase smoke of the 1R4F control. In addition to using the $1 \mathrm{R} 4 \mathrm{~F}$ compound concentrations as measurement standards, ethane deliveries of the $1 \mathrm{R} 4 \mathrm{~F}$ are used as an internal standard. Ethane is unaffected by filtration and is a good internal monitor of the amount of smoke that is formed during combustion. By normalizing the data to the ethane delivery, instrument and sample variations are minimized. In particular, the system is designed to reproducibly inject pressurized aliquots of gas-phase smoke into the system but from run to run, there is some variability built into the system. The pressurization of the sample, the timing of V4, or the split ratio can all be varied to change the amount of sample that gets on the column.

\section{DISCUSSION AND RESULTS}

The puff-by-puff GC-MS method is based upon the concept of multiplex chromatography (3-4), where timed sequential injections are made onto a single GC column. The chromatogram that results from a single injection of gas-phase smoke is shown in Figure 2. This is a total ion count (TIC) chromatogram of a $250-\mu \mathrm{L}$ injection of gas phase from puff 4 of $1 R 4 F$ directly into a GC-MS. Since this is a gas injection, there is no solvent peak. The first peak of this chromatogram contains the light gases such as oxygen, nitrogen, $\mathrm{CO}_{2}, \mathrm{CO}$, argon, and $\mathrm{H}_{2} \mathrm{O}$. Several of the larger peaks are identified as well. Figure 3 shows the same chromatographic environment but in this case there have been eight sequential injections of gas-phase smoke corresponding to the first eight puffs of a $1 \mathrm{R} 4 \mathrm{~F}$. Each puff was directly injected into the GC-MS immediately after being generated. P1-P8 are the peaks containing the light gases for each puff. 


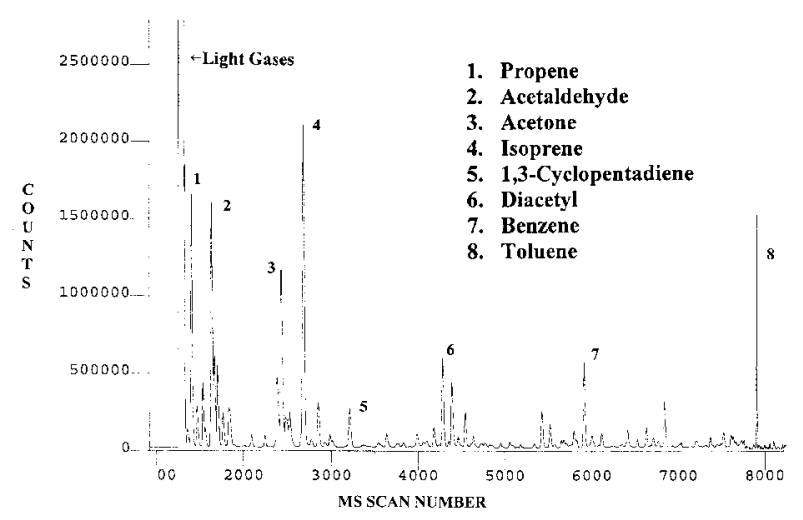

Figure 2.

Total ion chromatogram of a single injection of gas-phase cigarette smoke from puff 4 of a $1 \mathrm{R} 4 \mathrm{~F}$

The spaced injections result in a complex TIC chromatogram that is the sum of all injections. In order to extract analytical information from this type of chromatogram, individual peaks for gas-phase compounds are resolved by extracted-ion chromatography (EIC). In EIC, one or more ions that are in the mass spectrum of a given compound have been isolated from the rest of the ions in the TIC chromatogram. This simplifies the chromatographic details and allows the given compound to be resolved from co-eluting species. Also, since the compound is eluted in multiple peaks corresponding to the spaced injections of the gas phase of each puff, integration of the EIC chromatogram results in values for the individual concentrations of the compound delivered in each puff. It is this combination of selective ion monitoring and staggered retention times for the elution of the same chemical species that gives the method its power. In one chromatographic run averaging $45 \mathrm{~min}, 25$ separate chemical determinations are made on each puff.

An example of how EIC can resolve co-eluting compounds is shown in Figures 4 and 5. Figure 4 is the EIC chromatogram for the $30-m / z$ ion from 2 min through 11 $\mathrm{min}$. The $30-\mathrm{m} / \mathrm{z}$ ion is used to measure both ethane and formaldehyde. These peaks were not resolvable in the TIC chromatogram. The puff-by-puff profiles of these two compounds are now evident. Figure 5 is the EIC chromatogram of the $54-m / z$ ion for the same time region as used in Figure 3. It gives an entirely different chromatographic profile. The $54-\mathrm{m} / \mathrm{z}$ ion is used to measure butadiene. Butadiene also can be measured using the 43$\mathrm{m} / \mathrm{z}$ ion, but that ion also is present in the mass spectra of acetaldehyde and propene and there is some interference. Peak shape and retention times indicate that the multiplex sample injection system did not degrade the chromatography by overloading the column.

A series of cigarette samples was evaluated to demonstrate the capabilities of the puff-by-puff multiplex GC-MS smoke analysis system. The samples contained various amounts of activated carbon in the filters. Puff-by-puff

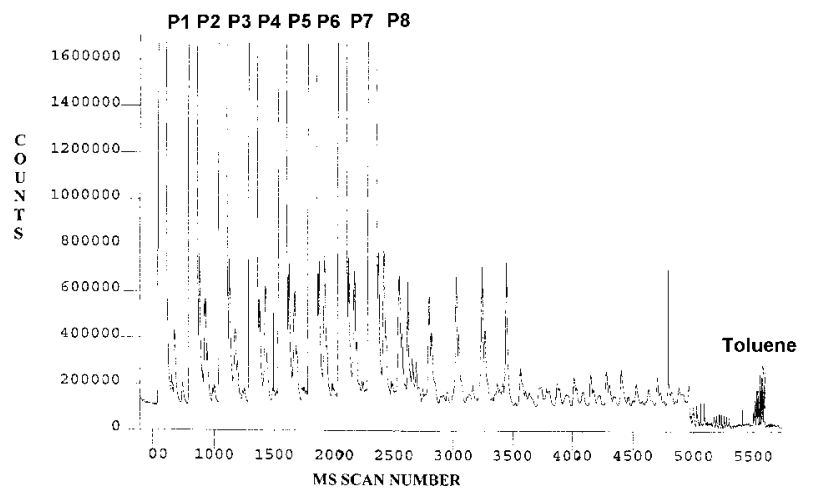

Figure 3.

Total ion chromatogram of multiplex injections of gas phase cigarette smoke from puffs 1 to 8 of a 1R4F; P1 through P8 are the light gases for each puff

data for various filtration materials yields valuable information on adsorption selectivity, capacity, and mechanisms. The effect of adsorbent capacity is demonstrated in Figure 6. The removal of acetaldehyde from a series of samples containing $0,25,50$, and $100 \mathrm{mg}$ of carbon are compared for puffs one and eight. It can be seen that while all carbon containing samples are effectively adsorbing acetaldehyde on puff one, this is no longer true on puff eight for the sample containing $25 \mathrm{mg}$ of carbon in the filter. Another aldehyde, formaldehyde, has an unusual concentration profile. Most mainstream smoke constituents gradually increase in concentration as a cigarette is puffed. This is attributed to an accumulation of condensate on the tobacco rod and a decrease in ventilation through the outerwrap cigarette paper as the cigarette is smoked. Formaldehyde is highest in concentration in the lighting puff (Figure 7). Cigarettes containing carbon in the filter significantly reduced the levels of formaldehyde in the lighting puff. Formaldehyde is removed from the mainstream smoke by physical adsorption to the high-surface area, porous adsorption materials. Physical adsorption is reversible and this phenomena is demonstrated in the second puff data from these cigarette samples. The deliveries of formaldehyde from the second and latter puffs of cigarettes containing an adsorbent in the filter are higher than the level delivered by the control cigarette. This is due to the volatile nature of formaldehyde and the capacity of the adsorption media. The higher molecular weight, less volatile, gases preferentially adsorb to the carbon surface. When the capacity of the adsorption media is limited, preferentially adsorbed smoke constituents displace more volatile smoke constituents adsorbed from previous puffs. This behavior also is noted in the latter puffs for smoke constituents such as hydrogen cyanide, propadiene, and carbonyl sulfide. It is noteworthy, however, that in all cases, the net amount of smoke constituent adsorbed by filtration materials is always less than the control cigarette on a total delivery per cigarette basis. 


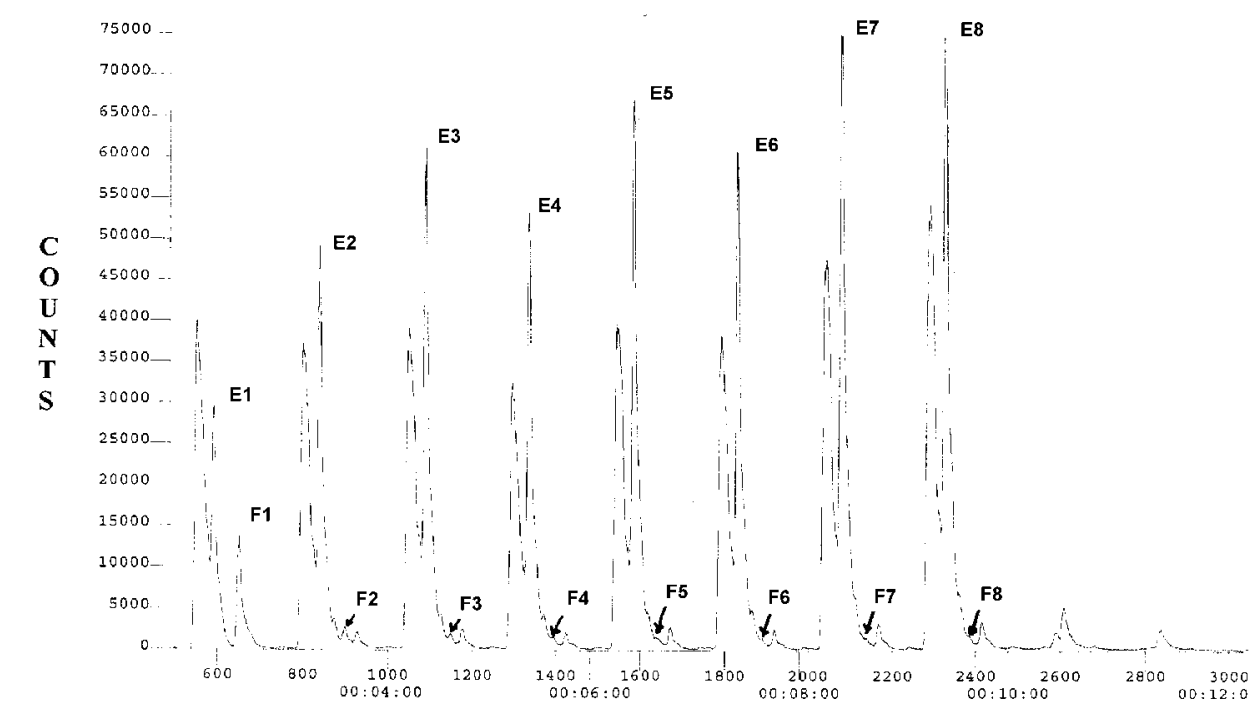

MS SCAN NUMBER

Figure 4.

lon chromatogram of the $30-\mathrm{m} / \mathrm{z}$ ion used to quantitate ethane and formaldehyde

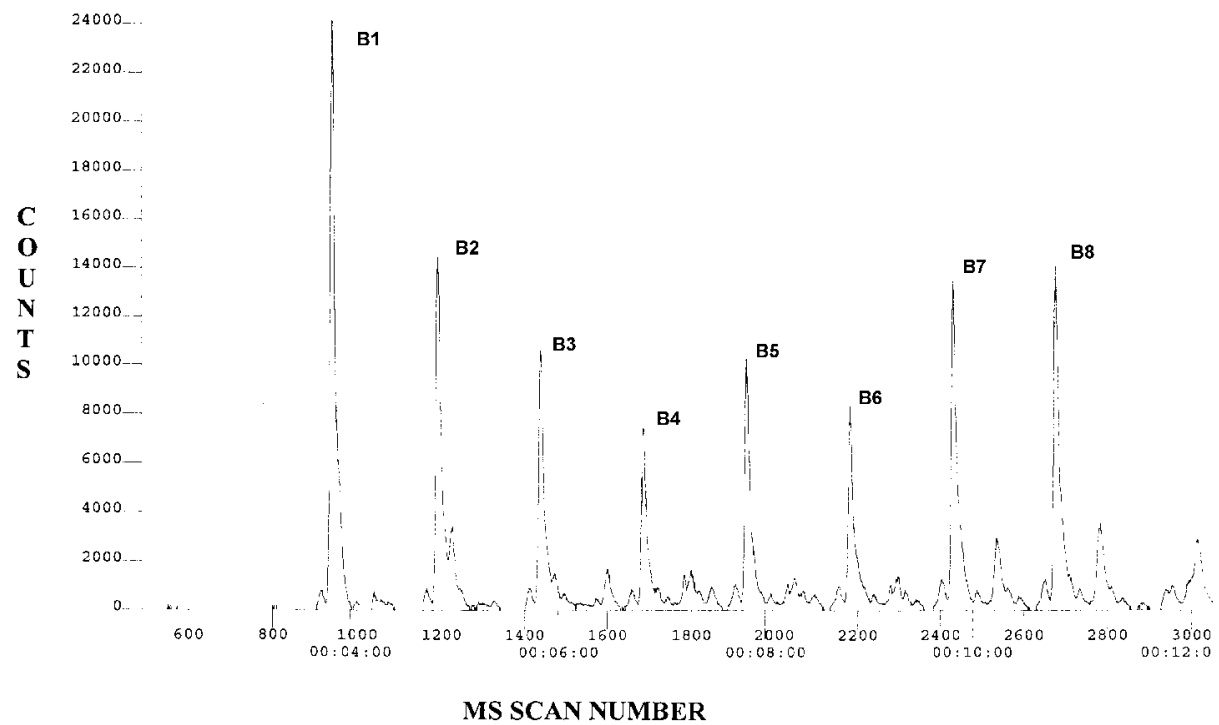

Figure 5.

Ion chromatogram of the $54-\mathrm{m} / \mathbf{z}$ ion used to quantitate butadiene

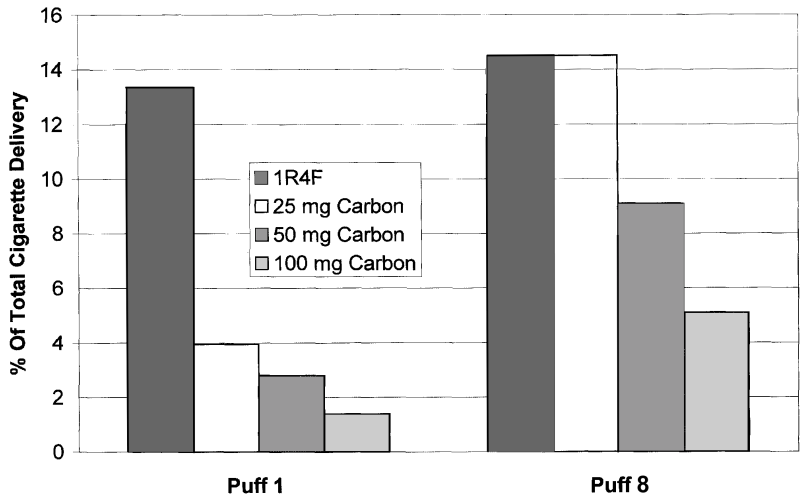

Figure 6.

Acetaldehyde filtration by carbon

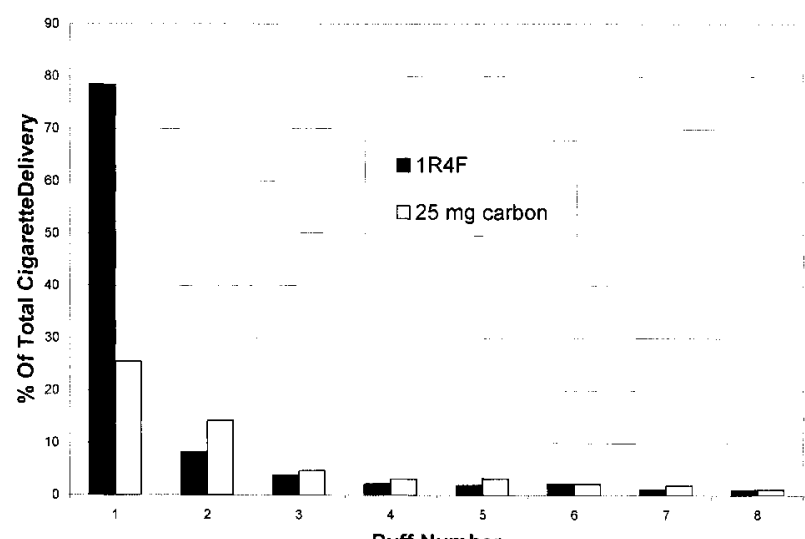

Figure 7.

Formaldehyde filtration by carbon 


\section{CONCLUSIONS}

The multiplex GC-MS smoke analysis system provides a means for rapid evaluation of cigarette prototypes. In particular, the system is a powerful tool for the study of improved, new, or existing filtration systems. Existing laboratory GC-MS systems can be modified at minimal expense by configuring the sample transfer system between an automated smoking machine and the GC inlet system. The measurement and analysis parameters for a variety of mainstream smoke constituents are made possible by the new software capabilities of the MS and the improved sampling control of the injection section of the chromatographic system.

\section{REFERENCES}

1. Seligman, R.B., F.E. Resnik, A.E. O'keeffe, J.C. Holmes, F.A. Morrell, D.P. Murrill, and F.L. Gager: Gas chromatography in tobacco research; Tob. Sci. 1 (1957) 120-125.
2. Koller, K., C. Thomas, M. Parrish, and D. Leyden: Puff-by puff determination of gas phase acetaldehyde, HCN, NO, and CO using FT-IR spectroscopy; Bull. Spéc. CORESTA, Symposium Kallithea, 1990, abstr. SO6, p. 211.

3. Zhang, M. and J. Philips: Applications of multiplex gas chromatography to the determination of organics in solid samples; J. Chrom. A, 689 (1995) 275-284.

4. Yang, M., Y. Luo, and J. Pawliszyn: Multiplex gas chromatography: A practical approach for environmental monitoring; TrAC 15 (1996) 273-278.

Address for correspondence

Philip Morris USA

P.O. Box 26583

USA - Richmond VA 23261 